\title{
Factors affecting livestock depredation by snow leopards (Panthera uncia) in the Himalayan region of Nepal
}

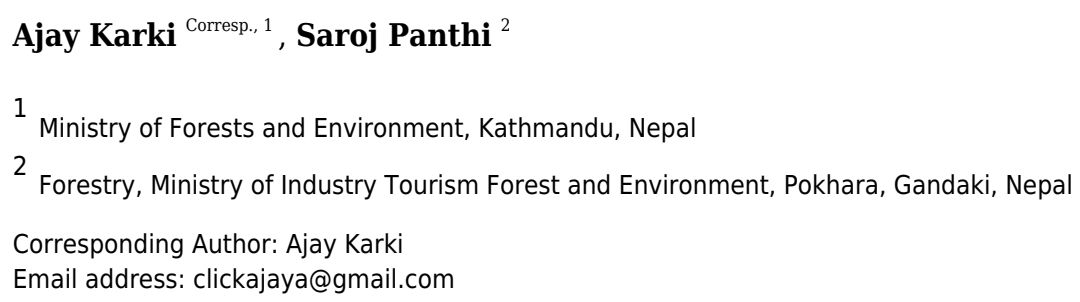

The snow leopard (Panthera uncia) found in central Asia is classified as vulnerable species by the International Union for Conservation of Nature (IUCN). Every year, large number of livestock are killed by snow leopards in Nepal, leading to economic loss to local communities and making human-snow leopard conflict a major threat to snow leopard conservation. We conducted formal and informal stakeholder's interviews to gather information related to livestock depredation with the aim to map the attack sites by the snow leopard. These sites were further validated by district forest office staffs to assess sources of bias. Attack sites older than 3 years were removed from the survey. We found 109 attack sites and visited all the sites for geo location purpose (GPS points of all unique sites were taken). We maintained at least a $100 \mathrm{~m}$ distance between attack locations to ensure that each attack location was unique, which resulted in 86 unique locations. A total of $235 \mathrm{~km}^{2}$ was used to define livestock depredation risk zone during this study. Using Maximum Entropy (MaxEnt) modeling, we found that distance to livestock sheds, distance to paths, aspect, and distance to roads were major contributing factors to the snow leopard's attacks. We identified $13.64 \mathrm{~km}^{2}$ as risk zone for livestock depredation from snow leopards in the study area. Furthermore, snow leopards preferred to attack livestock near livestock shelters, far from human paths and at moderate distance from motor roads.

These identified attack zones should be managed both for snow leopard conservation and livestock protection in order to balance human livelihoods while protecting snow leopards and their habitats. 
2 leopards (Panthera uncia) in the Himalayan region of

$4 \quad$ Ajay Karki $^{*}$, Saroj Panthi ${ }^{2}$

51 Ministry of Forests and Environment, Nepal

62 Ministry of Industry, Tourism, Forest and Environment, Gandaki Province, Pokhara, Nepal

7 * Corresponding author; Email: clickajaya@gmail.com 


\section{Abstract}

10 The snow leopard (Panthera uncia) found in central Asia is classified as vulnerable species by the

11 International Union for Conservation of Nature (IUCN). Every year, large number of livestock are

12 killed by snow leopards in Nepal, leading to economic loss to local communities and making

13 human-snow leopard conflict a major threat to snow leopard conservation. We conducted formal

14 and informal stakeholder's interviews to gather information related to livestock depredation with

15 the aim to map the attack sites by the snow leopard. These sites were further validated by district

16 forest office staffs to assess sources of bias. Attack sites older than 3 years were removed from the

17 survey. We found 109 attack sites and visited all the sites for geo location purpose (GPS points of

18 all unique sites were taken). We maintained at least a $100 \mathrm{~m}$ distance between attack locations to

19 ensure that each attack location was unique, which resulted in 86 unique locations. A total of 235

$20 \mathrm{~km}^{2}$ was used to define livestock depredation risk zone during this study. Using Maximum Entropy

21 (MaxEnt) modeling, we found that distance to livestock sheds, distance to paths, aspect, and

22 distance to roads were major contributing factors to the snow leopard's attacks. We identified

$2313.64 \mathrm{~km}^{2}$ as risk zone for livestock depredation from snow leopards in the study area.

24 Furthermore, snow leopards preferred to attack livestock near livestock shelters, far from human

25 paths and at moderate distance from motor roads. These identified attack zones should be managed

26 both for snow leopard conservation and livestock protection in order to balance human livelihoods

27 while protecting snow leopards and their habitats.

28 Keywords: Conflict, snow leopard, livestock depredation, modeling, wildlife management 


\section{Introduction}

30 The snow leopard (Panthera uncia) is a wild carnivore native to 12 countries in central Asia

31 (China, Bhutan, Nepal, India, Pakistan, Afghanistan, Tajikistan, Uzbekistan, Kyrgyzstan,

32 Kazakhstan, Russia, and Mongolia) (McCarthy et al., 2017). The home range of this species is

124-207 km² (Johansson et al., 2016) but estimated at 11-37 km² in Nepal's Himalaya (Jackson;

1996). In Qilianshan National Nature Reserve, China, the density of snow leopard is 3.31

individuals per $100 \mathrm{~km}^{2}$ (Alexander et al., 2015) Nepal has extremely variable population density;

for example Langu valley has 10-12 animals per $100 \mathrm{~km}^{2}$ and Manang has 5-7 animals per 100

$37 \mathrm{~km}^{2}$ (DNPWC, 2017). The primary prey targeted by snow leopards include wild species such as

blue sheep (Pseudois nayaur) and marmots (Marmota caudate) as well as domesticated livestock such as yak (Bos grunniens) and sheep (Ovis spp.) (Aryal et al., 2014; Weiskopf et al., 2016). Snow leopards co-exist with other Himalayan carnivores, such as red fox (Vulpes vulpes), grey wolf (Canis lupus), Eurasian lynx (Lynx lynx) and dhole (Cuonal pinus) (Alexander et al., 2016a; Bocci et al., 2017). Male snow leopards represent a greater threat to livestock than females (Chetri et al., 2017). While there are several studies characterizing snow leopards, their habits and habitats, there is a need for more localized information to improve conservation management practices.

Human-snow leopard conflict, especially related to livestock depredation, represents a major threat to snow leopards (Li et al., 2013; Mijiddorj et al., 2018; Suryawanshi et al., 2013; Ud Din et al., 2017; Wegge et al., 2012). Livestock grazing in snow leopard habitat has been seen to be a serious conservation threat to this species (Ghoshal et al., 2017; Khanal et al., 2018; Sharma et al., 2015). One of the main stressors of snow leopard poaching was found to be retaliatory killing as a consequence of livestock depredation (Maheshwari and Niraj, 2018). Another important factor influencing snow leopard poaching is the illegal trade of the body parts and pelts (Hussain, 2003), 
52 which is also on the rise ( $\mathrm{Li}$ and $\mathrm{Lu}, 2014)$. Furthermore, impacts of climate change have emerged

53 as a primary threat to snow leopards; their habitats are expected to shrink throughout their range

54 (Aryal et al., 2016; Li et al., 2016).

55 Mitigating human-snow leopard conflict through community engagement is one of the major

56 objectives of the snow leopard conservation action plan for Nepal (2017-2021) (DNPWC, 2017).

57 Research has shown that visitors are willing to pay for snow leopard conservation in the Annapurna

58 Conservation Area in Nepal (Schutgens et al., 2018) but more research is needed on snow leopard

59 interactions with human activities to better understand the influence of snow leopards on livestock

60 herding practices and vice-versa (Alexander et al., 2016b).

61 This study was conducted to identify the major factors affecting the risk of livestock depredation

62 from snow leopards. We also identified the potential snow leopard attack risk zone within the study

63 area. We hypothesized that anthropogenic variables are correlated with livestock depredation risk

64 from snow leopards than environmental and topographic factors.

65 Materials and methods

66 Study area

67 The study was conducted in the southeastern part of Manang District, Nepal covering a total area 68 of $235 \mathrm{~km}^{2}$ which is the jurisdiction of the District Forest Office (Now, Division Forest Office)

69 (Figure 1). We chose extent of study area by making $3 \mathrm{~km}$ buffering from livestock sheds.

70 According to the herders and livestock owners, livestock travel for grazing up to $3 \mathrm{~km}$ and some

71 of them travel in valley, rocks and glacier too. This distance was also validated and verified from

72 district forest office staffs who regularly patrol there. Further, the snowfields around the attack

73 zone is not permanent which allows seasonal grazing of livestock. Alongside, in rocky area small

Peer] reviewing PDF | (2020:08:51911:4:0:NEW 12 May 2021) 
74 livestock like goat and sheep roam easily, thus considered in the buffer. The study area is rich in 75 faunal and floral diversity. During the study, we recorded Himalayan pine (Pinus wallichiana),

east Himalayan fir (Abies spectabilis), Himalayan birch (Betula utilis), yew (Taxus baccata), figwort (Picrorhiza scrophulariiflora), marsh orchid (Dactylorhiza hatagirea), caterpillar fungus (Ophiocordyceps sinensis), felworts (Swertia chirata), love apple (Paris polyphylla), sunpati (Rhododendron anthopogon), sea buckthorn (Hippophae spp.), lokta (Daphne bholua), lily (Lilium nepalense), black juniper (Juniperus indica) as the major plant species in the study area. Snow leopard (Panthera uncia), musk deer (Moschus moschiferus), common leopard (Panthera pardus), impeyan pheasant (Lophophorus impejanus), Himalayan goral (Naemorhedus goral), wolf (Canis lupus), Asiatic black bear (Ursus thibetanus), barking deer (Muntiacus muntjac), gray langur (Semnopithecus schistaceus) are the major wild animals found in the study area.

Insert Figure-1 around here

\section{Plot design and data collection}

Firstly, we visited all possible risk zones ${ }^{1}$ for the livestock depredation by snow leopard in the study area between April and June, 2018. We prepared the list of herders in the study area, and then conducted a workshop ${ }^{2}$ of 5-8 herders and 3-5 villagers ${ }^{3}$ to gather information related to livestock depredation by snow leopard and finally mapped the attack sites. Workshop with herders were conducted at livestock sheds and workshops with villagers were conducted at villages. These sites were further validated by district forest office (now division forest office) staffs to check the biasness, if any. The study area is the habitat of common leopard and Asiatic black bear as well;

\footnotetext{
${ }^{1}$ Possible risk zones were identified based on proximity to shed, grazing/browsing pastures of livestock, grazing area where herders are normally absent

${ }^{2}$ A total of 17 workshops were conducted and participants were replicated in some workshops

${ }^{3}$ Only villagers who received the compensation for livestock depredation were considered for workshops to make sure that participants know the real information about attack sites
} 
94 however, they use lower elevation than snow leopard and there is no habitat overlap ${ }^{4}$ in livestock

95 attack zone. This was further confirmed by local herders, villagers and the forest staffs who

96 regularly patrol there. Wolf generally hunt on pack (with group). Due to hunting patterns,

97 information provided by herders and villagers, and verification by forest staffs, we confirmed that

98 we collected locations attacked by snow leopard, not by other carnivores. A total of 109 attack

99 sites in the last 3 years (2015 - 2018) were visited to record geo location (GPS points of all unique

100 sites were taken). We maintained at least a $100 \mathrm{~m}$ distance between attack locations to ensure that

101 each attack location is unique, resulting in 86 unique locations out of 109 collected.

102

103 Environmental variables

104 Topographical variables

105 Geographic factors are responsible for the spatial distribution of the snow leopard (Wolf and Ale,

106 2009). These geographic variables were used to model the habitat of this species and other

107 Himalayan carnivores in Nepal (Aryal et al., 2016; Bista et al., 2018; Panthi, 2018). A Digital

108 Elevation Model (DEM) with 30 m resolution was downloaded from the United States Geological

109 Survey (USGS) (https://earthexplorer.usgs.gov/). Slope and aspect were calculated from the DEM

110 using ArcGIS software (Table 1).

\section{Vegetative variables}

112 As the snow leopards are carnivores, their diet primarily consists of wild and domesticated

113 herbivores (Aryal et al., 2014; Wegge et al., 2012; Weiskopf et al., 2016), making vegetative

114 variables important to consider (Andersen et al., 2000). Therefore, forest cover of Global Forest

115 Change (GFC) http://earthenginepartners.appspot.com/science-2013-global-forest) was used as a

${ }^{4}$ Most of the attack zones are around $4000 \mathrm{~m}$ of altitude

Peer] reviewing PDF | (2020:08:51911:4:0:NEW 12 May 2021) 
116 vegetative variable (Hansen et al., 2013). We also included Enhanced Vegetation Index (EVI) to

117 model the potential attack risk of snow leopards. We downloaded EVI time series images from

118 2015, 2016, and 2017 from the Moderate Resolution Imaging Spectroradiometer (MODIS) sensor

119 from the USGS. Then, we used Environment for Visualizing Images (ENVI) software to smooth

120 the data by using an adaptive Savitzky-Golay filter in TIMESAT (Jönsson and Eklundh, 2004),

121 which reduced the cloud effect and allowed us to obtain mean, maximum, minimum and standard

122 deviation of EVI.

\section{Anthropogenic variables}

124 Large numbers of livestock are killed in Nepal due to the proximity of human settlements to the 125 natural range of snow leopards (Aryal et al., 2014; Wegge et al., 2012). Assessing anthropogenic

126 factors leading to livestock predation by snow leopards is critical as these are the variables that

127 represent the greatest degree of control from humans and would allow for achieving the stated

128 goals of snow leopard conservation and decreased livestock mortality from depredation. During

129 field data collection, human activities were documented in snow leopard habitat. We obtained the 130 shape file of motor roads and paths inside the study area from Geofabrik 131 (https://www.geofabrik.de/data/shapefiles.html). The locations of livestock shelter within snow 132 leopard habitat were collected during field work. Distance raster files of livestock shelters, 133 footpaths, and motor roads were created using ArcGIS. We downloaded land cover and land use 134 from the International Centre for Integrated Mountain Development (Uddin et al., 2015) and 135 included them in the model.

136

137 Insert table 1 around here 


\section{Modeling livestock depredation risk from snow leopards}

139 We used MaxEnt software to model the livestock depredation risk from snow leopard in the study 140 area. Geo-referenced presence points of livestock attacks by snow leopard and the environmental

141 variables (Table 1) were used as input variables to the MaxEnt model to produce a predictive 142 livestock depredation risk map (Elith et al., 2006; Phillips et al., 2017, 2006). The model was 143 validated by the area under receiver-operator curve (AUC) (Pearce and Ferrier, 2000) and 144 evaluated by True Skill Statistics (TSS) (Allouche et al., 2006). The multicollinearity between 145 variables was less than 0.7, which is acceptable for modeling (Dormann et al., 2013). Seventy 146 percent of the data were used to train the model and $30 \%$ were used to validate the model. We 147 used 10 replications, 1000 maximum iterations, and 1000 background points during the modeling 148 using reference from Barbet-Massin et al. (2012). The threshold to maximize the sum of specificity 149 and sensitivity was used to calculate TSS and to prepare the binary map from the continuous map 150 (Liu et al., 2013).

\section{Results}

\section{Snow leopard attack risk zone}

153 We identified $13.64 \mathrm{~km}^{2}$ as the potential risk zone for snow leopard attacks in the study area. The 154 areas with the highest risk for snow leopard attacks were identified spatially using ArcGIS (Figure 155 2). The AUC and TSS of the model were $0.941+/-0.013$ and $0.862+/-0.047$, respectively. A 156 threshold of 0.273 was used to prepare the risk map from the continuous probability map.

\section{Insert Figure -2, around here}

158 The most important variables found in the model to determine snow leopard attack risks are 159 distance to livestock sheds, distance to path, aspect, and distance to motor road (Figure 3). Other 
160 variables have less information to model the snow leopard attack risk. In figure $\mathbf{3}$, the regularized 161 gain of the model without distance to livestock shed was less than that of the model using other

162 single variables, therefore this is a more useful variable to the model. Similarly, the regularized 163 gain of the models without distance to path, aspect and distance to road are less, which also 164 demonstrates the high utility of these variables in modeling the snow leopard attack risk zone.

165 Insert Figure-3, around here

166 The regularized training gain of this figure explains how better the model distribution fits the 167 presence data compared to a uniform distribution. "With all variables" indicates the outcomes of 168 the model when all variables are used; "with only variable" denotes the effect of removing that 169 single variable. "Without variable" denotes the result when only that variable is used (Phillips, 170 2017). See Table 1 for full variable names and descriptions.

171

172 Snow leopard attacks on livestock are much more likely at closer distances to the shed which is 173 used to house the livestock (Figure 4A). Livestock are prone to attack by snow leopards far from 174 foot paths and at a moderate distance to motor roads (Figure 4B, D). At western aspect, the 175 probability of snow leopard attacks on livestock is high in comparison to other aspect (Figure 4C).

176 Our study area was small; the relationships may be different in other regions or in case of a larger 177 study area.

178 Insert Figure-4, around here 


\section{Discussion}

180 The southern and western sections of the study area are at the greatest risk of livestock depredation

181 from snow leopards. A portion of the west side of the study area is situated inside the Annapurna

182 Conservation Area (ACA) and other patches identified as risk zones are very near to the ACA, which likely indicates that snow leopards living in the ACA may come to these places to prey on livestock. We did not assess the proportion of the habitat used by snow leopard inside and outside the protected areas, however this study somehow supports the finding of Deguignet et al., (2014). Their study depicted that small proportion (14-19\%) of the species ranges in protected areas and primarily share the landscape with livestock herders. These patches were also identified by the interviewed respondents too as the good areas for livestock grazing, which is further evidenced by the high occurrence of livestock shelters. We surveyed only $235 \mathrm{~km}^{2}$, since the home range of this species is $124-207 \mathrm{~km}^{2}$ (Johansson et al., 2016), the total area may have retained only 2-3 individuals. However, a study indicates that Manang has 5-7 animals per $100 \mathrm{~km}^{2}$ (DNPWC, 2017), thus there might be more than 2-3 individuals in the study area.

Anthropogenic variables were identified as the most important factors influencing snow leopard attacks on livestock, and this finding is concurrent with existing literature. Multiple studies throughout the snow leopard's native range have recorded livestock depredation (Li et al., 2013; Mijiddorj et al., 2018; Suryawanshi et al., 2013; Ud Din et al., 2017; Wegge et al., 2012) and, in Nepal, the spatial distribution of snow leopard activities has been positively correlated with human activities (Wolf and Ale, 2009). Additionally, carnivore food requirement and spatial needs often conflict with human interest which is the major challenge for biodiversity conservation and maintaining the viable population (Treves and Karanth, 2003), this is supported by this study too.

Previous research has shown that the presence of livestock does not negatively affect the 
202 occurrence of snow leopards. Alongside, presence of higher livestock in grazing areas may have

203 affected the space used by wild prey which could have forced the snow leopard to prey on

204 livestock, which is supported by Karimov et al., (2018). In fact, snow leopards continue to hunt in

205 the areas close to livestock herding (Alexander et al., 2016; Rovero et al., 2018). The same finding

206 was supported by the results of this study. Alongside, Johansson et al., (2015); identified that snow

207 leopard preys on livestock mainly on stragglers and rugged areas where herders can't pay attention

208 for livestock.

209 Livestock predation by snow leopard is increased with livestock density (Suryawanshi et al.,

210 2017). Similarly, our research shows that proximity to livestock shelters is the variable most

211 closely associated with livestock depredation from snow leopards, which emphasizes the serious

212 nature of human-snow leopard conflict. If snow leopards attack livestock far from livestock

213 shelters, wildlife managers can restrict livestock from high risk areas and confine them to areas of

214 relative safety using shelter. However, our findings indicate that the areas near to livestock shelter

215 are at high risk of attack. Therefore, wildlife managers have to manage in such a way to allow for

216 the co-existence of livestock and snow leopards in pastureland.

217 Our study also identified a higher likelihood of snow leopard attack far from foot trails and at a

218 moderate distance from and motor roads. In the study area, there are many foot trails and a few

219 motor roads. Generally, the foot trails and motor roads have a steady flow of traffic, resulting in

220 few snow leopard attacks within direct proximity of foot trails and motor roads.

221 In order to achieve the goals of increasing conservation for snow leopards as well as decreasing

222 livestock depredation and economic loss from snow leopard attacks, the findings from this research

223 should be applied by herders in high risk zones. Given the high occurrence of attacks close to 
224 livestock shelters in the risk model, it is imperative that livestock herders utilize leopard-proof

225 sheds and that vigilant care is given, even near the shelters. The data indicates that leopards are

226 deterred from attacks in close proximity to humans, as shown by the lack of fit in the model at

227 close spatial scales to footpaths and motor roads, demonstrate the efficacy of human presence in

228 deterring snow leopard attacks. Further research is needed to determine if these results are

229 applicable in areas beyond that studied in this investigation as well as identifying other factors and

230 tactics that decrease human-snow leopard conflict.

231 It is noteworthy that MaxEnt software only considers the presence of livestock depredation by

232 snow leopards and is therefore limited because the risk model cannot account for the absence of

233 livestock attacks. Additionally, although we maintained at least $100 \mathrm{~m}$ in distance between

234 livestock attacks to ensure their uniqueness, we did not fully avoid spatial autocorrelation. The

235 statistical method to identify the minimum distance to deal with spatial autocorrelation may be

236 useful for a more robust model. We have collected presence locations of attack sites based mainly

237 on information provided by the herders and villagers, it may be biased and influence the result.

238 Therefore, the probability of showing attack sites of their proximity may be higher. Furthermore,

239 the snow leopard attack risk zone is also zone of livestock presence and livestock are vulnerable

240 to snow leopard depredation in these zones. Finally, while the distribution range of snow leopards

241 is extensive in the Manang district of Nepal, our study area is small and only represented a small

242 portion of the large and heterogeneous district.

\section{Conclusions}

244 This study identified the risk zone of snow leopard attacks in the Manang district of Nepal. The 245 southwestern part of the study area was found as the most vulnerable to snow leopard attacks. The 
246 distance to livestock shelters, distance to paths, aspect, and distance to roads are the most important

247 variables in defining the risk of snow leopard attacks in the study area. Snow leopards prefer to 248 attack livestock near livestock shelters and at moderate distances from roads. These identified 249 risk patches should be managed to conserve both the snow leopard and to protect the livestock.

250 The herders should be encouraged to protect their livestock through active caretaking, even in

251 close proximity to livestock sheds, and keeping them in leopard proof sheds, which will result in

252 less human-snow leopard conflict. Investigations of this nature should be conducted throughout 253 the snow leopard's range to determine the factors affecting livestock depredation by snow leopards 254 and to model snow leopard attack risk zones across its native range.

\section{Acknowledgements}

257

258

259

260

261

262

263

264

265

266

The study was conducted under the regular annual program of the Government of Nepal. We would like to acknowledge the Department of Forests in Nepal for allocating funding to this program. We would like to thank all of the staff of the District Forest office in Manang for their support during the entire study, especially during data collection, as well as the communities that participated in the study. We would like to thank Marcus E Taylor, Rajani Regmi and Shambhu Paudel for reviewing the language of the manuscript.

\section{Reference}

Alexander, J.S., Cusack, J.J., Pengju, C., Kun, S., Riordan, P., 2016a. Conservation of snow leopards: spill-over benefits for other carnivores? Oryx 50, 239-243. https://doi.org/10.1017/S0030605315001040 
267 Alexander, J.S., Gopalaswamy, A.M., Shi, K., Riordan, P., Margalida, A., 2015. Face value:

268 towards robust estimates of snow leopard densities. PLoS ONE 10, e0134815.

269 https://doi.org/10.1371/journal.pone.0134815

270 Alexander, J.S., Zhang, C., Shi, K., Riordan, P., 2016b. A spotlight on snow leopard

271 conservation in China. Integrative Zoology 11, 308-321. https://doi.org/10.1111/1749-

$272 \quad 4877.12204$

273 Allouche, O., Tsoar, A., Kadmon, R., 2006. Assessing the accuracy of species distribution

274 models : prevalence, kappa and the true skill statistic (TSS). Journal of Applied Ecology

275 43, 1223-1232. https://doi.org/10.1111/j.1365-2664.2006.01214.x

276

277

278

279

280

281

282

283

284

285

286

287

288

289

Andersen, M.C., Watts, J.M., Freilich, J.E., Yool, S.R., Wakefield, G.I., McCauley, J.F., Fahnestock, P.B., 2000. Regression-tree modelling of desert tortoise habitat in the central Mojave Desert. Ecological Applications 10, 890-900. https://doi.org/10.1890/10510761(2000)010[0890:RTMODT]2.0.CO;2

Aryal, A., Brunton, D., Ji, W., Karmacharya, D., McCarthy, T., Bencini, R., Raubenheimer, D., 2014. Multipronged strategy including genetic analysis for assessing conservation options for the snow leopard in the central Himalaya. Journal of Mammalogy 95, 871-881. https://doi.org/10.1644/13-MAMM-A-243

Aryal, A., Shrestha, U.B., Ji, W., Ale, S.B., Shrestha, S., Ingty, T., Maraseni, T., Cockfield, G., Raubenheimer, D., 2016. Predicting the distributions of predator (snow leopard) and prey (blue sheep) under climate change in the Himalaya. Ecology and Evolution 6, 4065-4075. https://doi.org/10.1002/ece3.2196

Barbet-Massin, M., Jiguet, F., Albert, C.H., Thuiller, W., 2012. Selecting pseudo-absences for species distribution models: how, where and how many? Methods in Ecology and Evolution 
291

292

293

294

295

296

297

298

299

300

301

302

303

304

305

306

307

308

309

310

311

312

Bista, M., Panthi, S., Weiskopf, S.R., 2018. Habitat overlap between Asiatic black bear Ursus thibetanus and red panda Ailurus fulgens in Himalaya. Plos One 13, e0203697. https://doi.org/10.1371/journal.pone.0203697

Bocci, A., Lovari, S., Khan, M.Z., Mori, E., 2017. Sympatric snow leopards and Tibetan wolves: coexistence of large carnivores with human-driven potential competition. European Journal of Wildlife Research 63, 92. https://doi.org/10.1007/s10344-017-1151-0

Chetri, M., Odden, M., Wegge, P., 2017. Snow leopard and himalayan wolf: food habits and prey selection in the central Himalayas, Nepal. PLoS ONE 12, e0170549. https://doi.org/10.1371/journal.pone.0170549

DNPWC, 2017. Snow leopard conservation action plan for Nepal (2017-2021), Department of National Parks and Wildlife Conservation.

Deguignet, M., Juffe-Bignoli, D., Harrison, J., MacSharry, B., Burgess, N., Kingston, N., 2014. 2014 United Nations List of Protected Areas. UNEP-WCMC, Cambridge.

Dormann, C.F., Elith, J., Bacher, S., Buchmann, C., Carl, G., Carré, G., 2013. Collinearity: A review of methods to deal with it and a simulation study evaluating their performance. Ecography 36, 027-046.

Elith, J., H. Graham, C., P. Anderson, R., Dudík, M., Ferrier, S., Guisan, A., J. Hijmans, R., Huettmann, F., R. Leathwick, J., Lehmann, A., Li, J., G. Lohmann, L., A. Loiselle, B., Manion, G., Moritz, C., Nakamura, M., Nakazawa, Y., McC. M. Overton, J., Townsend Peterson, A., J. Phillips, S., Richardson, K., Scachetti-Pereira, R., E. Schapire, R., Soberón, J., Williams, S., S. Wisz, M., E. Zimmermann, N., 2006. Novel methods improve prediction of species' distributions from occurrence data. Ecography 29, 129-151. 
314 Ghoshal, A., Bhatnagar, Y.V., Pandav, B., Sharma, K., Mishra, C., Raghunath, R., Suryawanshi, K.R., 2017. Assessing changes in distribution of the endangered snow leopard Panthera uncia and its wild prey over 2 decades in the Indian Himalaya through interview-based

Hansen, M.C.C., Potapov, P. V, Moore, R., Hancher, M., Turubanova, S.A. a, Tyukavina, A., Thau, D., Stehman, S.V. V, Goetz, S.J.J., Loveland, T.R.R., Kommareddy, A., Egorov, A., Chini, L., Justice, C.O.O., Townshend, J.R.G.R.G., Patapov, P.V., Moore, R., Hancher, M., Turubanova, S.A. a, Tyukavina, A., Thau, D., Stehman, S.V. V, Goetz, S.J.J., Loveland, conservation of the snow leopard Panthera uncia in Api Nampa Conservation Area, Nepal. 
Oryx 1-8. https://doi.org/10.1017/S0030605318000145

337

Li, J., Lu, Z., 2014. Snow leopard poaching and trade in China 2000-2013. Biological Conservation 176, 207-211. https://doi.org/10.1016/j.biocon.2014.05.025

Li, J., McCarthy, T.M., Wang, H., Weckworth, B. V., Schaller, G.B., Mishra, C., Lu, Z., Beissinger, S.R., 2016. Climate refugia of snow leopards in High Asia. Biological Conservation 203, 188-196. https://doi.org/10.1016/j.biocon.2016.09.026

Li, J., Yin, H., Wang, D., Jiagong, Z., Lu, Z., 2013. Human-snow leopard conflicts in the Sanjiangyuan region of the Tibetan Plateau. Biological Conservation 166, 118-123. https://doi.org/10.1016/j.biocon.2013.06.024

Liu, C., White, M., Newell, G., 2013. Selecting thresholds for the prediction of species occurrence with presence-only data. Journal of Biogeography 40, 778-789. https://doi.org/10.1111/jbi.12058

Maheshwari, A., Niraj, S.K., 2018. Monitoring illegal trade in snow leopards: 2003-2014. Global Ecology and Conservation 14, e00387. https://doi.org/10.1016/j.gecco.2018.e00387

Mccarthy, T., Mallon, D., Jackson, R., Zahler, P., McCarthy, K.P., 2017. Panthera uncia. The IUCN Red List of Threatened Species. https://doi.org/10.2305/IUCN.UK.20172.RLTS.T22732A50664030.en

Mijiddorj, T.N., Alexander, J.S., Samelius, G., 2018. Livestock depredation by large carnivores in the South Gobi, Mongolia. Wildlife Research 45, 237-246. https://doi.org/10.1071/WR18009

Panthi, S., 2018. Predicting current and future habitat suitability for red pandas in Nepal. MSc thesis. University of Twente,faculty of geoinformation and earth observation, Enschede, Netherlands. 
359 Pearce, J., Ferrier, S., 2000. Evaluating the predictive performance of habitat models developed

360 using logistic regression. Ecological Modelling 133, 225-245.

$361 \quad$ https://doi.org/10.1016/S0304-3800(00)00322-7

362 Phillips, S.J., 2017. A brief tutorial on Maxent. https://doi.org/10.4016/33172.01

363 Phillips, S.J., Anderson, R.P., DudÍk, M., Schapire, R.E., Blair, M.E., 2017. Opening the black

364 box: an open-source release of Maxent. Ecography 40, 1-7.

365 https://doi.org/10.1111/ecog.03049

366

367

368

369

370

371

372

373

374

375

376

377

378

379

380

381

Phillips, S.J., Anderson, R.P., Schapire, R.E., 2006. Maximum entropy modelling of species geographic distributions. Ecological Modelling 190, 231-259.

https://doi.org/10.1016/j.ecolmodel.2005.03.026

Schutgens, M.G., Hanson, J.H., Baral, N., Ale, S.B., 2018. Visitors' willingness to pay for snow leopard Panthera uncia conservation in the Annapurna conservation Area, Nepal. Oryx 110. https://doi.org/10.1017/S0030605317001636

Sharma, R.K., Bhatnagar, Y.V., Mishra, C., 2015. Does livestock benefit snow leopards. Biological Conservation 190, 8-13. https://doi.org/https://doi.org/10.1016/j.biocon.2015.04.026

Suryawanshi, K.R., Bhatnagar, Y.V., Redpath, S., Mishra, C., 2013. People, predators and perceptions: patterns of livestock depredation by snow leopards and wolves. Journal of Applied Ecology 50, 550-560. https://doi.org/10.1111/1365-2664.12061

Suryawanshi, K.R., Redpath, S.M., Bhatnagar, Y.V., Ramakrishnan, U., Chaturvedi, V., Smout, S.C., Mishra, C., 2017. Impact of wild prey availability on livestock predation by snow leopards. Royal Society Open Science 4. https://doi.org/10.1098/rsos.170026

Treves, A and Karanth K.U., 2003. Human-Carnivore Conflict and Perspectives on Carnivore 
382

383

384

385

386

387

388

389

390

391

392

393

394

395

396

397

398

399

400

\section{.}

Management Worldwide. Conservation Biology, 17 (6), 1491-1499, doi https://doi.org/10.1111/j.1523-1739.2003.00059.x

Ud Din, J., Ali, H., Ali, A., Younus, M., Mehmood, T., Norma-Rashid, Y., Ali Nawaz, M., 2017. Pastoralist-predator interaction at the roof of the world: Conflict dynamics and implications for conservation. Ecology and Society 22, 32. https://doi.org/10.5751/ES-09348-220232

Uddin, K., Shrestha, H.L., Murthy, M.S.R., Bajracharya, B., Shrestha, B., Gilani, H., Pradhan, S., Dangol, B., 2015. Development of 2010 national land cover database for the Nepal. Journal of Environmental Management 148, 82-90. https://doi.org/10.1016/j.jenvman.2014.07.047

Wegge, P., Shrestha, R., Flagstad, Ø., 2012. Snow leopard Panthera uncia predation on livestock and wild prey in a mountain valley in northern Nepal: implications for conservation management. Wildlife Biology 18, 131-141. https://doi.org/10.2981/11-049

Weiskopf, S.R., Kachel, S.M., McCarthy, K.P., 2016. What are snow leopards really eating? Identifying bias in food-habit studies. Wildlife Society Bulletin. https://doi.org/10.1002/wsb.640

Wolf, M., Ale, S., 2009. Signs at the top: habitat features influencing snow leopard Uncia uncia activity in Sagarmatha national park, Nepal. Journal of Mammalogy 90, 604-611. https://doi.org/10.1644/08-MAMM-A-002R1.1 
Figure 1

Study Area
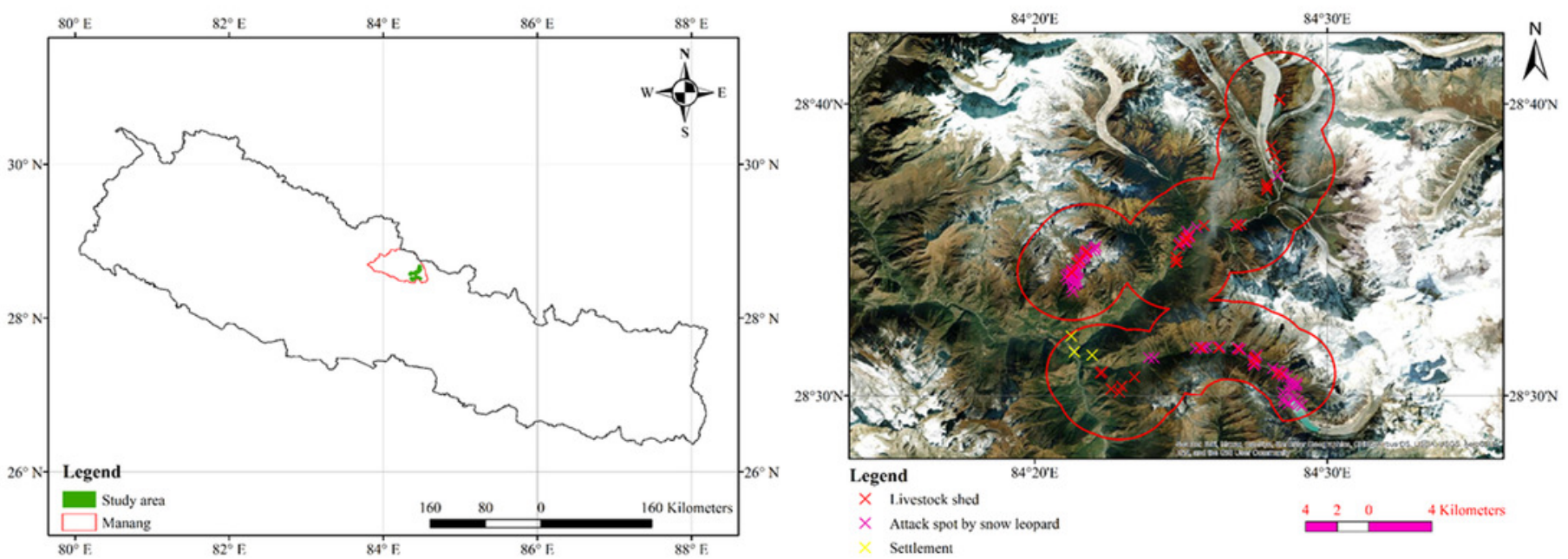
Figure 2

Mapping of attack risk zone by snow leopard

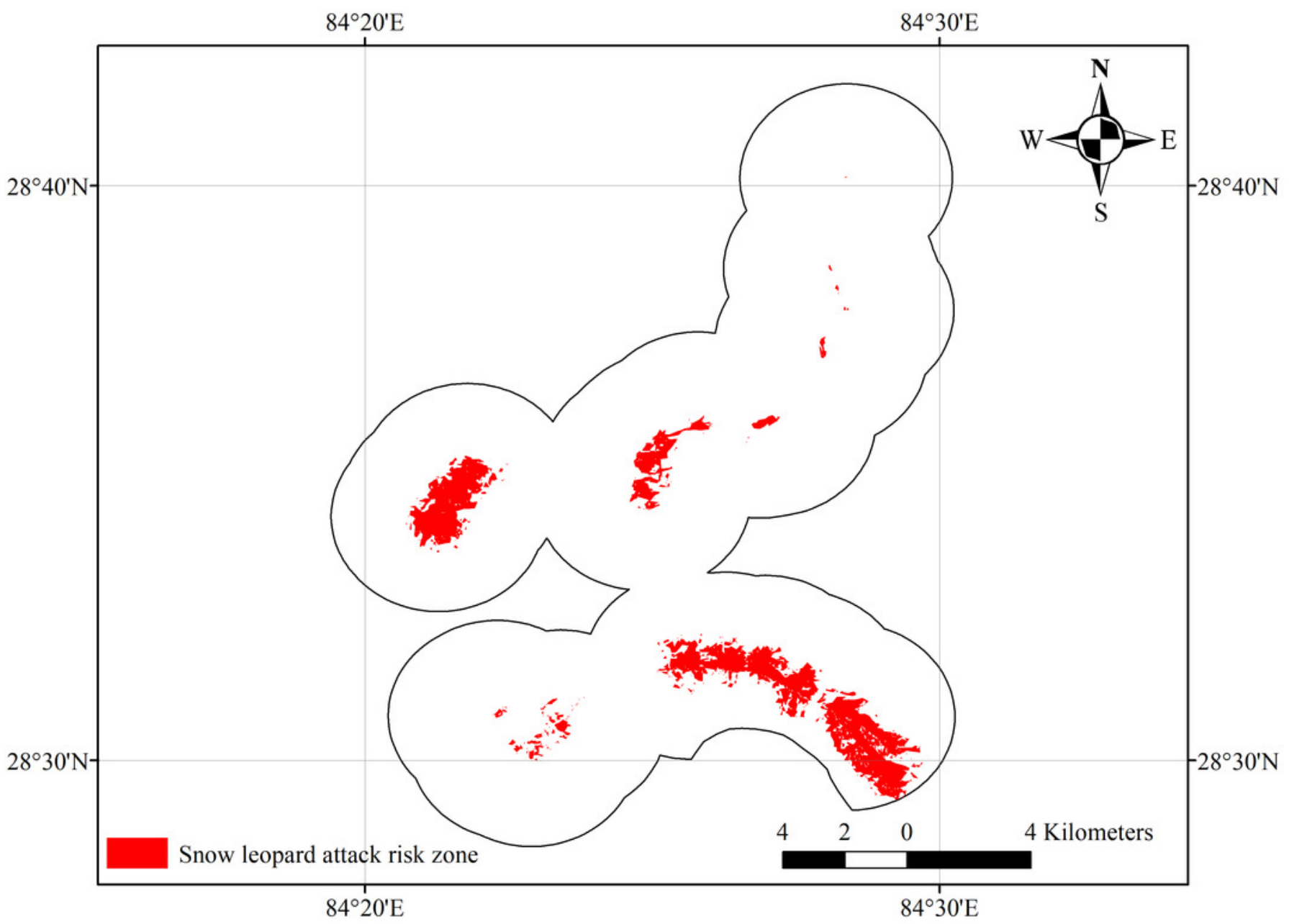


Figure 3

Importance of variables to train the model. The regularized training gain explains how much better the model distribution fits the presence data relative to a uniform distribution. "With all variables" indicates the results of the model when all variables

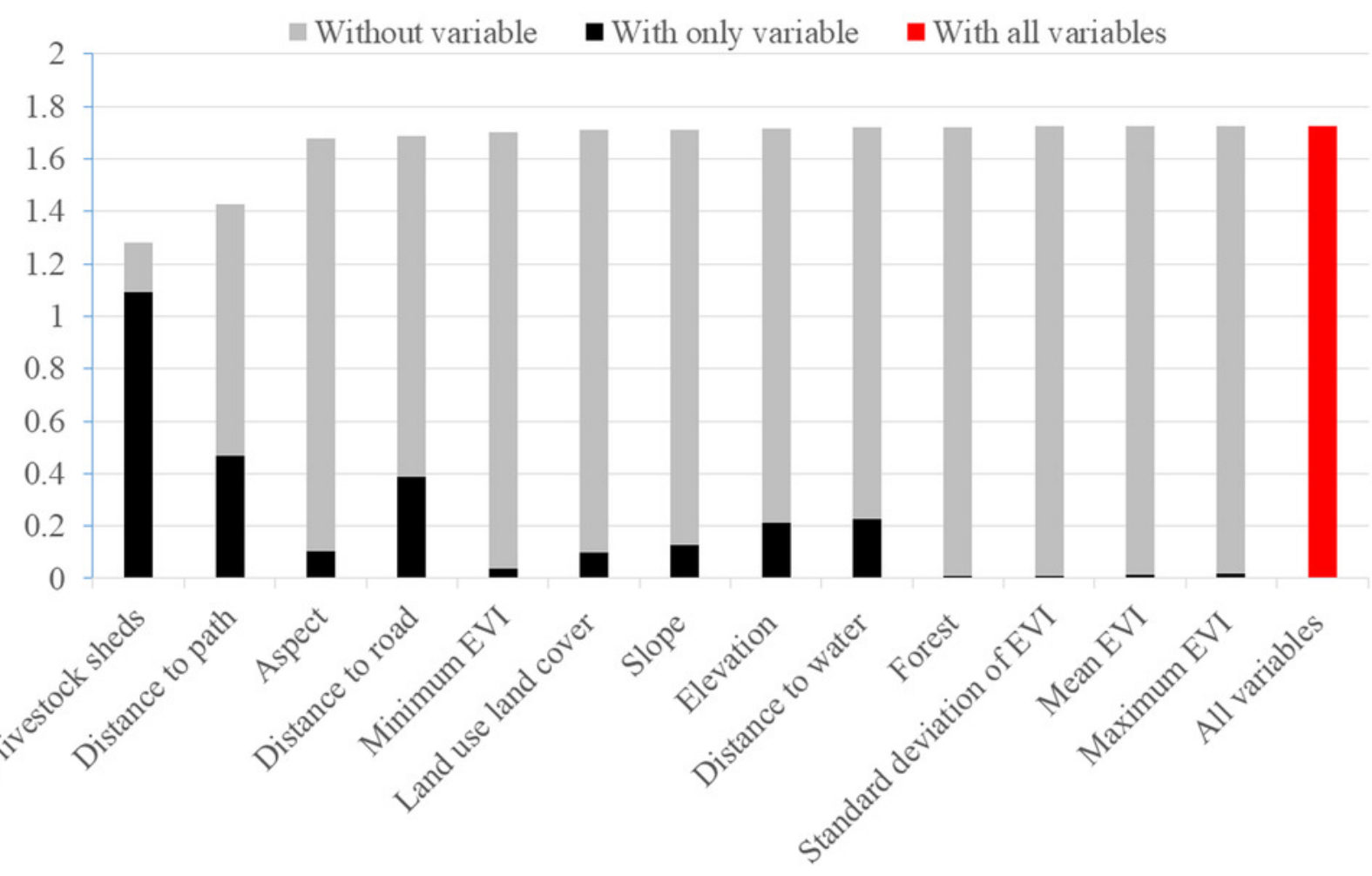


Figure 4

Variable relationship and importance
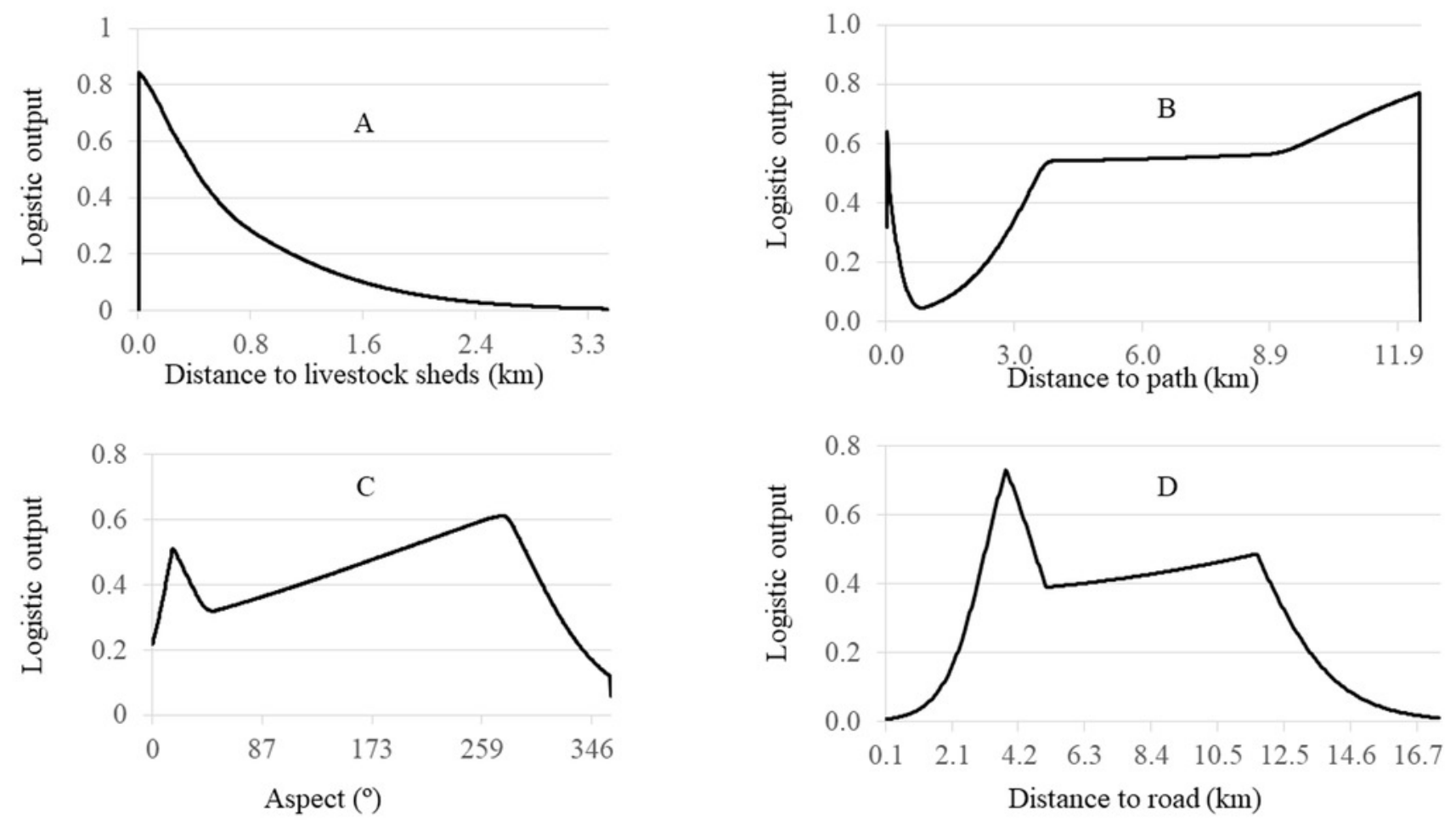
Table $\mathbf{1}$ (on next page)

Table 1 


\begin{tabular}{|c|c|c|c|c|}
\hline Source & Category & Variable & Abbreviation & Unit \\
\hline \multirow{3}{*}{ USGS } & \multirow[t]{4}{*}{ Topographic } & Elevation & elevation & $\mathrm{m}$ \\
\hline & & Aspect & aspect & Degree \\
\hline & & Slope & slope & Degree \\
\hline GEOFABRIK & & Distance to water & dist_water & $\mathrm{m}$ \\
\hline \multirow{4}{*}{ MODIS } & \multirow{5}{*}{$\begin{array}{l}\text { Vegetation- } \\
\text { related }\end{array}$} & Mean EVI & evimean & Dimensionless \\
\hline & & Maximum EVI & evimax & Dimensionless \\
\hline & & Minimum EVI & evimin & Dimensionless \\
\hline & & $\begin{array}{l}\text { Standard deviation of } \\
\text { EVI }\end{array}$ & evisd & Dimensionless \\
\hline GFC & & Forest & forest & Dimensionless \\
\hline \multirow[t]{3}{*}{ GEOFABRIK } & \multirow[t]{4}{*}{ Anthropogenic } & $\begin{array}{l}\text { Distance to livestock } \\
\text { shelter }\end{array}$ & dist_goth & $\mathrm{m}$ \\
\hline & & Distance to motor road & dist_motor & $\mathrm{m}$ \\
\hline & & Distance to path & dist_path & $\mathrm{m}$ \\
\hline ICIMOD & & Land use/land cover & landcover & $\mathrm{m}$ \\
\hline
\end{tabular}

